\title{
Hypertension and Management
}

REVIEW ARTICLE

\section{Preeclampsia: Pathophysiology and the Maternal-Fetal Risk}

\section{Gibran Khalil $^{1}$ and Afshan Hameed ${ }^{2 *}$}

${ }^{1}$ Research Volunteer, University of California, Irvine, USA

${ }^{2}$ Professor, Department of Obstetrics \& Gynecology, University of California, Irvine, USA

*Corresponding author: Afshan B Hameed, Professor, Department of Obstetrics \& Gynecology, Cardiology, Medical Director of Obstetrics, Quality and Safety, University of California, Irvine, USA, Tel: 714-456-7879, Fax: 714-456-7091, E-mail: ahameed@uci.edu

\section{What is Preeclampsia?}

Preeclampsia complicates about $5 \%$ of all pregnancies worldwide and is one of the leading causes of maternal and fetal morbidity and even mortality [1]. The disorder is specific to pregnancy characterized by new onset of hypertension and end-organ dysfunction including proteinuria after 20 weeks of gestation. Preeclampsia usually presents during pregnancy; however, it may sometimes manifest in the postpartum period in a previously normotensive woman. Hypertension in pregnancy is defined as blood pressure of greater than $140 \mathrm{mmHg}$ systolic or $90 \mathrm{mmHg}$ diastolic, or both. Proteinuria is spillage of $300 \mathrm{mg}$ or more of protein in a 24 hour urine collection or a protein to creatinine ratio of $0.3 \mathrm{mg} / \mathrm{dL}$ using a spot urine protein and spot urine creatinine $[2,3]$.

Preeclampsia is further sub-classified into various categories based on the severity of disease [4]. The term "preeclampsia without severe features" is defined as hypertension with proteinuria (formerly called as "mild preeclampsia") without symptoms and/or additional abnormalities in the laboratory testing. The term "preeclampsia with severe features" has been recently re-defined as blood pressure of greater than $160 \mathrm{mmHg}$ systolic or diastolic greater than $110 \mathrm{mmHg}$, or both plus evidence of end organ dysfunction (Table 1). Eclampsia is the convulsive phase of preeclampsia that is characterized by generalized tonic-clonic seizure activity. It is commonly preceded by premonitory symptoms such as a severe headache, hyperreflexia, blurred vision, photophobia, epigastric or right upper quadrant pain, and/ or mental status changes. HELLP syndrome is a constellation of laboratory abnormalities (Hemolysis, Elevated
Liver enzymes, and Low Platelets). This diagnosis is considered to be a subtype of preeclampsia and generally occurs without significant elevations of blood pressure.

Chronic hypertension on the other hand, is preexisting hypertension diagnosed prior to pregnancy or before the $20^{\text {th }}$ week of gestation. Typically, blood pressure does not worsen during pregnancy and the patient remains hypertensive after the conventional postpartum period of six to eight weeks. It is important to differentiate it from gestational hypertension which is a diagnosis of exclusion for pregnant women who do not meet the criteria for preeclampsia or chronic hypertension [5].

\section{What is the Pathophysiology of Preeclampsia?}

The exact pathophysiology of preeclampsia remains unknown. However, there are several theories that have been put forth that may explain most of the abnormalities seen in this disease process [6].

\section{Abnormal placentation}

Preeclampsia is primarily a disease of the placenta as it may be encountered in molar pregnancies [7]. One of the most accepted theories in preeclampsia revolves around abnormal placentation. In normal pregnancies,

Table 1: End organ dysfunction in preeclampsia.

\begin{tabular}{|c|c|}
\hline Thrombocytopenia & Platelet count $<100,000 /$ micro L \\
\hline Liver dysfunction & $\begin{array}{l}\text { AST or ALT > } 2 \text { times the upper } \\
\text { limit of normal }\end{array}$ \\
\hline Renal insufficiency & $\begin{array}{l}\text { Creatinine }>1.1 \mathrm{mg} / \mathrm{dL} \text { or doubling } \\
\text { of baseline creatinine }\end{array}$ \\
\hline \multicolumn{2}{|l|}{ Pulmonary edema } \\
\hline $\begin{array}{l}\text { Central nervous system } \\
\text { disturbances }\end{array}$ & $\begin{array}{l}\text { Severe headache, scotomata, } \\
\text { altered mental status }\end{array}$ \\
\hline
\end{tabular}

Adapted from $[2,4]$.

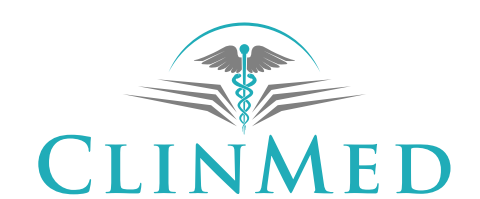

INTERNATIONAL LIBRARY

Citation: Khalil G, Hameed A (2017) Preeclampsia: Pathophysiology and the Maternal-Fetal Risk. J Hypertens Manag 3:024. doi.org/10.23937/2474-3690/1510024

Received: February 28, 2017: Accepted: May 22, 2017: Published: May 25, 2017

Copyright: (c) 2017 Khalil G, et al. This is an open-access article distributed under the terms of the Creative Commons Attribution License, which permits unrestricted use, distribution, and reproduction in any medium, provided the original author and source are credited. 
trophoblast begins invasion into the myometrial blood vessels by remodeling the maternal spiral arteries, transforming them from small, muscular, higher resistance arterioles into large caliber arteries with high capacitance and free flow of blood [8]. Remodeling typically begins in the late first trimester and is completed by 1820 weeks of gestation. Failure of this process of complete remodeling leads to persistence of high resistance spiral arteries that impede placental perfusion thereby leading to a state of "relative hypoxemia" which culminates into maternal endothelial cell dysfunction. Maternal systemic endothelial cell dysfunction manifests in signs and symptoms that are reflective of maternal vasoconstriction and multi-organ damage outlined in Table 1. Placental hypo perfusion is both a cause and effect of abnormal Placentation $[9,10]$ that becomes more pronounced with growing needs of the feto-placental unit as pregnancy progresses. Late pathologic changes that are seen in the placental tissue correlate with ischemia including atherosis, fibrinoid necrosis, thrombosis, sclerosis of the arterioles, and infarction [11].

\section{Immunologic factors}

Preeclampsia tends to affect the first pregnancy (naive to the paternal/fetal antigens) and repeat exposure to paternal/fetal antigens tends to lower the risk of the disease. Additionally, other situations that limit exposure to paternal antigens such as a new partner in a subsequent pregnancy and long inter-pregnancy intervals, use barrier contraception, or conception through artificial insemination lead to a higher risk of preeclampsia. It is also known that women who conceive through egg donation have more than double the risk of preeclampsia than other forms of assisted reproduction [12]. Pregnancies conceived through assisted reproductive techniques had a four-fold increase in preeclampsia compared to naturally conceived pregnancies [13]. Abnormalities seen in preeclampsia are similar to those seen in graft versus host disease. The interaction between the extra villous trophoblast antigens and the natural killer cells dictates placental implantation. In preeclampsia abnormal placental implantation is thought to be due to the increased NK cell activity due to the conflict between the maternal and paternal genes. This may partly be mediated through the dendritic cell activity as increased dendritic cell infiltration is seen in placental bed biopsies in preeclampsia [14].

\section{Inflammation and/or infection}

Signs of inflammation are seen in normal pregnancies at term, but these changes are exaggerated in women with preeclampsia. It is thought that debris of the outer layer of trophoblast contributes to maternal inflammation and some features of the syndrome. Placental DNA released into the circulation of the mother and the fetus (maternal circulation) could have a role in the characteristic inflammation involved with preeclampsia [14]. In studies that looked at the connection between maternal infection and preeclampsia, it was found that the risk of preeclampsia was increased in women with urinary tract infection and periodontal disease [15-17].

\section{Genetic factors}

Genetic factors are thought to have a role in getting the disease $[18,19]$. Observations that suggest this are that women who are pregnant for the first time and have a family history of preeclampsia have a higher risk of getting it than women who are pregnant for the first time and do not have a family history of preeclampsia [20]. The risk of preeclampsia is significantly increased in women who previously had preeclampsia. The partners of men who whose mothers had preeclampsia are more likely to get preeclampsia. A woman who gets pregnant by a man whose previous spouse had preeclampsia is at a higher risk of the disease. Most of the data suggests that the mother's and father's genes have a role in the defective formation of the placenta and subsequent preeclampsia [21].

To summarize, placental hypoxia and ischemia are the ultimate pathways in the pathogenesis of preeclampsia $[22,23]$ by release of vasoactive factors into the maternal circulation and endothelial cell dysfunction leading to the signs and symptoms of preeclampsia.

\section{What are the Risk Factors for Preeclampsia?}

There are several well-studied risk factors for preeclampsia and the magnitude of risk is dependent on the individual factor, severity and the number of risk factors (Table 2). The highest risk being maternal antiphospholipid antibody syndrome: a nine-fold increased risk for developing preeclampsia followed by history of preeclampsia in a prior pregnancy that confers a seven-fold increased risk. Additionally, the greater severity of preeclampsia in prior pregnancy is associated with a higher risk for preeclampsia in subsequent gestation [24]. Others factors include diabetes, hypertension, multiple gestation, African American background, assisted reproduction and obesity [25].

\section{How Does Preeclampsia Affect Mother and}

Table 2: Risk factors for preeclampsia.

\begin{tabular}{|l|l|}
\hline 1 & First pregnancy \\
\hline 2 & Prior preeclampsia \\
\hline 3 & Chronic hypertension \\
\hline 4 & Obesity \\
\hline 5 & Chronic renal disease \\
\hline 6 & History of thrombophilia \\
\hline 7 & Multiple gestation \\
\hline 8 & Assisted reproductive techniques \\
\hline 9 & Family history of preeclampsia \\
\hline 10 & Type I or Type II diabetes mellitus \\
\hline 11 & Obesity \\
\hline 12 & Age $>40$ \\
\hline 13 & Prolonged pregnancy interval \\
\hline 14 & African american race \\
\hline 15 & Molar pregnancy \\
\hline
\end{tabular}

Adapted from $[24,25]$. 


\section{the Fetus?}

A compromised placental perfusion leads to a decrease in blood flow to the developing fetus. Fetal complications include premature birth, fetal growth restriction, and placental abruption. Maternal complications are primarily related to the organ system damage including pulmonary edema, seizures, renal failure, liver hematoma/rupture, and bleeding complications [2]. Histologically, the classic findings in the maternal kidneys are swelling and enlargement of the endothelial cells of glomerular capillaries [26]. Ocular involvement can present with retinal vasospasm and retinal edema. Retinal detachment and cortical blindness may occur in extreme cases. Fortunately, blindness is uncommon and usually temporary, resolving within hours to days of delivery [27].

\section{What are the Maternal Outcomes Associated with Preeclampsia?}

Eclampsia complicates 2-3\% of women diagnosed with preeclampsia with severe features who are not receiving anti-seizure prophylaxis (magnesium sulfate) and up to $0.6 \%$ of women diagnosed with preeclampsia without severe features [6]. Eclampsia may lead to significant maternal morbidity and even mortality. Maternal sequelae include and not limited to intracerebral hemorrhage, transient blindness, and cardiorespiratory arrest. Permanent neurologic sequelae from brain ischemia or hemorrhage are the most common causes of maternal death, with the maternal mortality rate ranging from $0-14 \%[5]$.

\section{What are the Fetal Outcomes in Preeclamp- sia?}

Placental perfusion is decreased in preeclampsia, and the primary consequences are intrauterine growth restriction of the fetus and oligohydramnios [28]. Perinatal death is primarily related to premature delivery, placental abruption, and intrauterine asphyxia. According to Liu, et al. the purported fetal death rate in a population-based cohort study is 10.8 per 1000 births [3] with both fetal morbidity and mortality closely related to gestational age at the time of eclampsia. Fetal outcomes in pregnancies complicated by preeclampsia are largely influenced by gestational age at time of delivery. Neonatal complications such as necrotizing enterocolitis, respiratory distress syndrome, and intraventricular hemorrhage among women with preeclampsia are comparable to gestational age matched non-hypertensive controls [7].

What are the Management Principles in Preeclampsia?

Given that the underlying disease process of preeclampsia lies in the placental tissue, the cure is delivery of the placenta. For women diagnosed with preeclamp- sia without severe features, delivery is generally recommended at 37 weeks gestation [8], and in the presence of severe features, delivery is recommended at 34 weeks or earlier for maternal or fetal instability. Induction of labor and vaginal delivery is preferred whenever possible. Antihypertensive therapy is reserved for blood pressure greater than $160 \mathrm{mmHg}$ systolic or $110 \mathrm{mmHg}$ diastolic. Commonly used antihypertensive medications for acute management include labetalol and hydralazine. Magnesium sulfate is indicated for seizure (eclampsia) prophylaxis particularly in a setting of preeclampsia with severe features [10]. Magnesium sulphate is considered superior to other anticonvulsant agents [11]. The exact mechanism of action of magnesium sulphate remains unknown; it is thought that it acts as a 1) Vasodilator 2) Protectant against cerebral edema and 3) Central anticonvulsant [12].

\section{Can Preeclampsia be Prevented?}

Given the risk to the mother and the fetus, numerous interventions have been tried to prevent preeclampsia. Unfortunately, none has proven useful for the primary prevention of preeclampsia. In a subset of women with a prior pregnancy complicated by preeclampsia, use of low dose aspirin is beneficial. Cochrane meta-analysis demonstrated a $17 \%$ risk reduction in preeclampsia with the use of antiplatelet agents with a significant decrease in absolute risk reduction in women at high risk for disease [13]. ACOG Task Force on Hypertension in Pregnancy recommends initiating low-dose aspirin in the late first trimester for women with a history of preeclampsia with subsequent delivery at or before 34 weeks gestation [2].

How to Counsel Women with Risk Factors for Preeclampsia or Prior Pregnancy Complicated by Preeclampsia?

For women with risk factors for preeclampsia (Table 2), preconception counseling is important as it provides an opportunity to identify potentially modifiable risk factors. Ideally, a comprehensive history and physical examination and relevant laboratory tests should be obtained early in pregnancy to establish a baseline to compare to at a later gestational age. Women should made aware of the common sign and symptoms of preeclampsia and be closely monitored for the disease process. Women should also be informed of the increased risk of future cardiovascular disease.

\section{What is the Recurrence Risk or Preeclampsia?}

Preeclampsia increases the risk of recurrent disease in a subsequent pregnancy. Approximately $20 \%$ of women with preeclampsia will develop pregnancy-related hypertension and $16 \%$ will be diagnosed with preeclampsia in subsequent pregnancies [29-32].

Are Women with Preeclampsia at Risk for Fu- 


\section{ture Cardiovascular Disease?}

Preeclampsia and pregnancy-related hypertensive disorders have been recognized as major risk factors for the development of future cardiovascular disease. Pregnancy is considered at stress test for the cardiovascular system [29,33-35].

\section{Conclusions}

Preeclampsia is new onset of hypertension along with proteinuria after 20 weeks of gestation which may be associated with multiple organ dysfunctions. The precise etiology of preeclampsia remains known, however, several theories that have been put forth. Preeclampsia affects both mother and the fetus, and is one of the most important causes of maternal morbidity and even mortality.

\section{References}

1. Abalos E, Cuesta C, Grosso AL, Chou D, Say L (2013) Global and regional estimates of preeclampsia and eclampsia: a systematic review. Eur J Obstet Gynecol Reprod Biol 170: 1-7.

2. American College of Obstetricians and Gynecologists; Task Force on Hypertension in Pregnancy (2013) Hypertension in pregnancy. Report of the American College of Obstetricians and Gynecologists' Task Force on Hypertension in Pregnancy. Obstet Gynecol 122: 1122-1131.

3. Payne B, Magee LA, von Dadelszen P (2011) Assessment, surveillance and prognosis in pre-eclampsia. Best Pract Res Clin Obstet Gynaecol 25: 449-462.

4. Tranquilli AL, Brown MA, Zeeman GG, Dekker G, Sibai BM (2013) The definition of severe and early-onset preeclampsia. Statements from the International Society for the Study of Hypertension in Pregnancy (ISSHP). Pregnancy Hypertens 3: 44-47.

5. Helewa ME, Burrows RF, Smith J, Williams K, Brain P, et al. (1997) Report of the Canadian Hypertension Society Consensus Conference: 1. Definitions, evaluation and classification of hypertensive disorders in pregnancy. CMAJ 157: 715-725.

6. Ahmed A, Rezai H, Broadway-Stringer S (2016) Evidence-Based Revised View of the Pathophysiology of Preeclampsia. Adv Exp Med Biol 956: 355-374.

7. Clark E Nugent, Margaret R Punch, Mason Barr Jr, Laurie LeBlanc, Mark P Johnson, et al. (1996) Persistence of partial molar placenta and severe preeclampsia after selective termination in a twin pregnancy. Obstetrics \& Gynecology 87: 829-831.

8. Lim KH, Zhou Y, Janatpour M, McMaster M, Bass K, et al. (1997) Human cytotrophoblast differentiation/invasion is abnormal in pre-eclampsia. Am J Pathol 151: 1809-1818.

9. Alasztics B, Kukor Z, Panczel Z, Valent S (2012) The pathophysiology of preeclampsia in view of the two-stage model. Orv Hetil 153: 1167-1176.

10. Cheng MH, Wang PH (2009) Placentation abnormalities in the pathophysiology of preeclampsia. Expert Rev Mol Diagn 9: 37-49.

11. Maqueo M, Chavezazuela J, Dosaldelavega M (1964) Placental Pathology in Eclampsia and Preeclampsia. Obstet Gynecol 24: 350-356.

12. Blazquez A, Garcia D, Rodriguez A, Vassena R, Figuer- as $F$, et al. (2016) Is oocyte donation a risk factor for preeclampsia? A systematic review and meta-analysis. J Assist Reprod Genet 33: 855-863.

13. Lynch A, McDuffie R Jr, Murphy J, Faber K, Orleans M (2002) Preeclampsia in multiple gestation: the role of assisted reproductive technologies. Obstet Gynecol 99: 445451.

14. LaMarca BD, Ryan MJ, Gilbert JS, Murphy SR, Granger JP (2007) Inflammatory cytokines in the pathophysiology of hypertension during preeclampsia. Curr Hypertens Rep 9: $480-485$.

15. Conde-Agudelo A, Villar J, Lindheimer M (2008) Maternal infection and risk of preeclampsia: systematic review and metaanalysis. Am J Obstet Gynecol 198: 7-22.

16. Easter SR, Cantonwine DE, Zera CA, Lim KH, Parry SI, et al. (2016) Urinary tract infection during pregnancy, angiogenic factor profiles, and risk of preeclampsia. Am J Obstet Gynecol 214: e1-e7.

17. Haggerty CL, Klebanoff MA, Panum I, Uldum SA, Bass DC, et al. (2013) Prenatal Chlamydia trachomatis infection increases the risk of preeclampsia. Pregnancy Hypertens 3 : 151-154.

18. Oudejans CB, van Dijk M, Oosterkamp M, Lachmeijer A, Blankenstein MA (2007) Genetics of preeclampsia: paradigm shifts. Hum Genet 120: 607-612.

19. Cox B (2014) Bioinformatic approach to the genetics of preeclampsia. Obstet Gynecol 124: 633.

20. Dawson LM, Parfrey PS, Hefferton D, Dicks EL, Cooper MJ, et al. (2002) Familial risk of preeclampsia in Newfoundland: a population-based study. J Am Soc Nephrol 13: 1901-1906.

21. Dekker G, Robillard PY, Roberts C (2011) The etiology of preeclampsia: the role of the father. J Reprod Immunol 89: 126-132.

22. Granger JP, Alexander BT, Llinas MT, Bennett WA, Khalil RA (2002) Pathophysiology of preeclampsia: linking placental ischemia/hypoxia with microvascular dysfunction. Microcirculation 9: 147-160.

23. Rampersad R, Nelson DM (2007) Trophoblast biology, responses to hypoxia and placental dysfunction in preeclampsia. Front Biosci 12: 2447-2456.

24. Sibai BM, Gordon T, Thom E, Caritis SN, Klebanoff M, et al. (1995) Risk factors for preeclampsia in healthy nulliparous women: a prospective multicenter study. The National Institute of Child Health and Human Development Network of Maternal-Fetal Medicine Units. Am J Obstet Gynecol 172: 642-648.

25. Pare E, Parry S, McElrath TF, Pucci D, Newton A, et al. (2014) Clinical risk factors for preeclampsia in the 21st century. Obstet Gynecol 124: 763-770.

26. Prudence A Hill, Kenneth F Fairley, Priscilla Kincaid-Smith, Matthew Zimmerman, Graeme B Ryan (1988) Morphologic changes in the renal glomerulus and the juxtaglomerular apparatus in human preeclampsia. J Pathol 156: 291-303.

27. Jaffe G, Schatz H (1987) Ocular manifestations of preeclampsia. Am J Ophthalmol 103: 309-315.

28. Weiner E, Schreiber L, Grinstein E, Feldstein O, Rymer-Haskel N, et al. (2016) The placental component and obstetric outcome in severe preeclampsia with and without HELLP syndrome. Placenta 47: 99-104.

29. Enkhmaa D, Wall D, Mehta PK, Stuart JJ, Rich-Edwards 
JW, et al. (2016) Preeclampsia and Vascular Function: A Window to Future Cardiovascular Disease Risk. J Womens Health (Larchmt) 25: 284-291.

30. Fabio Facchinetti, Luca Marozio, Tiziana Frusca, Elvira Grandone, Paolo Venturini, et al. (2009) Maternal thrombophilia and the risk of recurrence of preeclampsia. Am J Obstet Gynecol 200: 46.e1-46.e5.

31. Melamed N, Hadar E, Peled Y, Hod M, Wiznitzer A, et al. (2012) Risk for recurrence of preeclampsia and outcome of subsequent pregnancy in women with preeclampsia in their first pregnancy. J Matern Fetal Neonatal Med 25: 22482251.

32. Sibai BM, Mercer B, Sarinoglu C (1991) Severe preeclamp- sia in the second trimester: recurrence risk and long-term prognosis. Am J Obstet Gynecol 165: 1408-1412.

33. Heidema WM, Scholten RR, Lotgering FK, Spaanderman ME (2015) History of preeclampsia is more predictive of cardiometabolic and cardiovascular risk factors than obesity. Eur J Obstet Gynecol Reprod Biol 194: 189-193.

34. van Kesteren F, Visser S, Hermes W, Teunissen PW, Franx A, et al. (2016) Counselling and management of cardiovascular risk factors after preeclampsia. Hypertens Pregnancy 35: 55-61.

35. Veerbeek JH, Hermes W, Breimer AY, van Rijn BB, Koenen SV, et al. (2015) Cardiovascular disease risk factors after early-onset preeclampsia, late-onset preeclampsia, and pregnancy-induced hypertension. Hypertension 65: 600-606. 